\title{
Intercellular Adhesion Molecule-1 K469E and Angiotensinogen T207M Polymorphisms in Coronary Slow Flow
}

\author{
Emine Gazi ${ }^{\mathrm{a}}$ Ahmet Barutcu ${ }^{\mathrm{a}}$ Burak Altun ${ }^{\mathrm{a}} \quad$ Ahmet Temiz $^{\mathrm{a}} \quad$ Adem Bekler $^{\mathrm{a}}$ \\ Mine Urfali $^{\mathrm{b}}$ Fatma Silan $^{\mathrm{b}}$ Yucel Colkesen ${ }^{\mathrm{a}}$ Ozturk Ozdemir $^{\mathrm{b}}$ \\ Departments of a Cardiology and ${ }^{b}$ Medical Genetics, Faculty of Medicine, Çanakkale Onsekiz Mart University, \\ Çanakkale, Turkey
}

\section{Key Words}

ICAM1 polymorphism · Angiotensinogen polymorphism .

Coronary slow flow $\cdot$ Atherosclerosis

\begin{abstract}
Objective: To investigate intercellular adhesion molecule-1 (ICAM1) and angiotensinogen (AGT) gene polymorphisms, as related to atherosclerosis and endothelial dysfunction, in coronary slow flow (CSF). Subjects and Methods: The participants in this study were 48 patients with CSF and 67 patients with normal coronary flow as controls. The K469E polymorphism of ICAM1 (rs5498) and the T207M polymorphism of $A G T$ (rs4762) were determined using the polymerase chain reaction amplification method. Results: Baseline demographic parameters were similar in both groups. The mean thrombolysis in myocardial infarction frame count was significantly higher in patients with CSF $(23.8 \pm 5.1)$ compared to the controls $(13.3 \pm 2.6, p<0.001)$. A significant association was found between the ICAM1 Kallele and CSF (OR: $1.96,95 \% \mathrm{Cl}: 1.15-3.35, \mathrm{p}=0.013)$. There was no difference in the frequency of $A G T$ T207M genotypes in the patients with CSF and the control subjects. Conclusion: This study showed that K469E polymorphisms of ICAM1 that play a role in atherosclerotic pathogenesis are related to CSF.
\end{abstract}

(c) 2014 S. Karger AG, Basel

\begin{tabular}{ll}
\hline KARGER & $\begin{array}{l}\text { ( } 2014 \text { S. Karger AG, Basel } \\
1011-7571 / 14 / 0234-0346 \$ 39.50 / 0\end{array}$ \\
$\begin{array}{l}\text { E-Mail karger@karger.com } \\
\text { www.karger.com/mpp }\end{array}$ & $\begin{array}{l}\text { This is an Open Access article licensed under the terms of the } \\
\text { Creative Commons Attribution-NonCommercial 3.0 Un- } \\
\text { ported license (CC BY-NC) (www.karger.com/OA-license), } \\
\text { applicable to the online version of the article only. Distribu- } \\
\text { tion permitted for non-commercial purposes only. }\end{array}$
\end{tabular}

\section{Introduction}

Cardiovascular diseases (CVD) worldwide are the most common cause of mortality, and atherosclerosis is the most common cause of CVD [1,2]. Endothelial dysfunction is an important change seen in the subclinical stages of atherosclerosis $[3,4]$. There are many molecules and cytokines that play important roles in endothelial functions. One molecule that is well studied is the intercellular adhesion molecule-1 (ICAM1) which is a member of the immunoglobulin family. It is released from endothelial cells, small muscle cells, macrophages, and lymphocytes $[5,6]$. The important role which ICAM1 plays in inflammation and atherosclerosis is due to the induction of leukocyte adhesion and transmigration to vascular basal membranes [5, 6]. ICAM1 K469E polymorphism (rs5498) increases the serum levels and functions of the ICAM1 molecule and is closely related to the formation and progression of atherosclerosis [7-9].

Angiotensinogen (AGT) is a key molecule in the reninangiotensin-aldosterone system (RAS), and it plays an important role in the regulation of blood pressure [10]. $A G T$ is changed to angiotensin I via renin, and angiotensin I is converted to angiotensin II (Ag-II). Ag-II plays a role in the etiopathogenesis of atherosclerosis resulting from the release of cytokines and adhesion molecules

Dr. Emine Gazi, MD

Department of Cardiology, Faculty of Medicine

Çanakkale Onsekiz Mart University

TR-17100 Çanakkale (Turkey)

E-Mail eordulu@ hotmail.com 
from vascular endothelial cells [11]. Previous studies showed that AGT gene polymorphisms lead to increased AGT levels and are related to hypertension and coronary artery disease $[2,12-14]$.

Atherosclerosis is a major underlying pathophysiological mechanism in CVD $[1,2]$. Coronary slow flow (CSF) is described as the delayed angiographic passage of a contrast agent in the absence of stenosis in epicardial coronary arteries [15]. Previous studies have shown that endothelial dysfunction and diffuse atherosclerosis may be the underlying mechanisms in the etiopathogenesis of CSF, although the etiopathogenesis is still unclear [16, 17]. However, it was shown that certain polymorphisms are associated with CSF $[18,19]$. We hypothesized that CSF is a subtype of atherosclerotic disease; hence, we aimed in this study to investigate the relationship between CSF with AGT T207M and ICAM1 K469E polymorphisms (http://www.genenames.org) that were previously reported to be associated with atherosclerosis and endothelial dysfunction.

\section{Subjects and Methods}

\section{Study Population}

48 patients with CSF and 67 controls with normal coronary arteries participated in this study. Coronary angiography was performed in our Cardiology Clinic (Çanakkale, Turkey) between June 2010 and June 2013 on patients who had an indication for coronary angiography. All the subjects agreed to participate in the research and signed the informed consent form, and permission was obtained from the institution's Ethics Committee. The patients' complete history, results of the physical examination, risk factors for atherosclerotic heart disease, and medications were recorded. Patients who had been treated with antihypertensive drugs or those whose baseline blood pressure exceeded 140/90 mm Hg were diagnosed with hypertension. Diabetes mellitus was defined as fasting blood glucose higher than $126 \mathrm{mg} / \mathrm{dl}$ or the use of antidiabetic medications. Hyperlipidemia was defined as a total cholesterol level $>200 \mathrm{mg} / \mathrm{dl}$ and/or a low-density cholesterol level $>160 \mathrm{mg} / \mathrm{dl}$. Exclusion criteria were patients with a known atherosclerotic disease, peripheral artery disease, visualized coronary plaques in coronary angiography, malignancy, chronic inflammatory disease, and renal and hepatic insufficiency. Peripheral blood samples from CSF patients and healthy controls were used to genotype point mutations of ICAM1 and AGT genes.

Thrombolysis in Myocardial Infarction Frame Count and Definition of CSF

Angiographic equipment (GE Medical Systems, Innova 2100, USA) was used to perform coronary angiography with a femoral approach using Judkins catheters and iopramide as a contrast agent (Ultravist-370, Bayer Schering Pharma, Germany). The frame rate was $30 \mathrm{fps}$, and angiograms were recorded on a compact disc in DICOM format. Coronary blood flow was measured quan- titatively using the thrombolysis in myocardial infarction (TIMI) frame count, which was determined for each major coronary artery in each participant according to the method first described by Gibson et al. [20]. The corrected TIMI frame counts for the left anterior descending coronary arteries (LAD) were calculated. The TIMI frame counts were divided by 1.7 because the LAD is usually longer than other major coronary arteries; thus, the TIMI frame count for this vessel is often higher. TIMI frame counts in the LAD and left circumflex (LCx) arteries were assessed at the right anterior oblique projection and in the right coronary artery (RCA) at the left anterior oblique projection. The mean TIMI frame count for each subject was calculated by adding the TIMI frame counts for LAD/1.7, LCx, and RCA, and divided by 3 . The corrected cutoff values were $36.2 \pm 2.6$ frames for LAD, $22.2 \pm 4.1$ frames for LCx, and $20.4 \pm 3$ frames for RCA. Any values obtained above these thresholds were considered CSF [20].

\section{Genotyping}

Peripheral blood samples were collected from the patients and controls after a 12-hour overnight fasting period. All routine biochemical tests were carried out with the Cobas 6000 Integra (Roche) autoanalyzer device using the chemiluminescence method. Venous blood was collected in EDTA tubes for isolation of genomic DNA; the tubes were stored at $-20^{\circ} \mathrm{C}$. In all, $115 \mathrm{DNA}$ samples from the patients with CSF and controls were genotyped using real-time PCR analysis. The total genomic DNA was extracted by either the MagnaPure Compact (Roche) technique or the Invitek kit extraction technique (Invitek ${ }^{\circledR}$; Invisorb Spin Blood, Berlin, Germany). Target genes were amplified using real-time PCR methods (LightCycler 2.0, Roche) for the CSF cohort and the healthy controls. LightCycler FastStart DNA Master HybProbes, $\mathrm{MgCl}_{2}$ (final concentration $3.0 \mathrm{mM}$ ), primer mix, PCR-grade water, and template DNA from the patients and controls were used for real-time amplification for each target gene.

The previously reported codon number of rs4762 is 207 (previously added as 174). T207M refers to a threonine-to-methionine exchange in codon 207. Real-time PCRs were performed using allele-specific sense and antisense SNP primers under the following conditions: initial denaturation at $95^{\circ} \mathrm{C}$ for $10 \mathrm{~min}, 45$ quantification cycles at $95^{\circ} \mathrm{C}$ for $10 \mathrm{~s}$, annealing at $60^{\circ} \mathrm{C}$ for $10 \mathrm{~s}$, and extension at $72^{\circ} \mathrm{C}$ for $15 \mathrm{~s}$. The melting cycle was $95^{\circ} \mathrm{C}$ for $30 \mathrm{~s}, 40^{\circ} \mathrm{C}$ for $2 \mathrm{~min}$, and final cooling at $40^{\circ} \mathrm{C}$ for $30 \mathrm{~s}$. The LightCycler 2.0 software program (Roche) was used to detect the mutated $\mathrm{C}$ allele (channel 640 at $58^{\circ} \mathrm{C}$ ) and wild T genotype (channel 640 at $66^{\circ} \mathrm{C}$ ) profiles for target analysis of AGT T207M.

The single nucleotide $A$ to $G$ polymorphism in the sixth exon of the ICAM1 gene (K469E) resulted in an amino acid substitution from glutamic acid (E) to lysine (K) (rs5498). Genomic DNA (300 ng) was amplified by a real-time PCR in a final volume of $20 \mu \mathrm{lus}$ ing the following conditions: initial denaturation at $95^{\circ} \mathrm{C}$ for 10 min, 45 quantification cycles at $95^{\circ} \mathrm{C}$ for $10 \mathrm{~s}$, annealing at $60^{\circ} \mathrm{C}$ for $10 \mathrm{~s}$, and extension at $72^{\circ} \mathrm{C}$ for $15 \mathrm{~s}$. The melting cycle was $95^{\circ} \mathrm{C}$ for $30 \mathrm{~s}, 40^{\circ} \mathrm{C}$ for $2 \mathrm{~min}$, and final cooling at $40^{\circ} \mathrm{C}$ for $30 \mathrm{~s}$. The LightCycler 2.0 software program (Roche) was used to detect the mutated $\mathrm{G}$ allele (channel 640 at $66.5^{\circ} \mathrm{C}$ ) and the wild A genotype (channel 640 at $55.8^{\circ} \mathrm{C}$ ) profiles for target analysis of ICAM1 K469E. 
Table 1. Baseline demographic and laboratory parameters of the study population

\begin{tabular}{lccl}
\hline & $\begin{array}{l}\text { CSF } \\
(\mathrm{n}=48)\end{array}$ & $\begin{array}{l}\text { Controls } \\
(\mathrm{n}=67)\end{array}$ & $\mathrm{p}$ \\
\hline Age, years & $56.0 \pm 10.3$ & $54.1 \pm 11.8$ & 0.460 \\
BMI & $27.7 \pm 3.5$ & $27.4 \pm 4.0$ & 0.744 \\
SBP, mm Hg & $126.8 \pm 12.5$ & $127.3 \pm 13.0$ & 0.867 \\
DBP, mm Hg & $77.7 \pm 8.4$ & $76.5 \pm 7.9$ & 0.485 \\
Heart rate, bpm & $70 \pm 11$ & $68 \pm 8$ & 0.936 \\
Males, $\mathrm{n}$ & $26(54.2)$ & $27(40.3)$ & 0.141 \\
Hypertension, $\mathrm{n}$ & $22(46.8)$ & $31(47.0)$ & 0.986 \\
Diabetes mellitus, $\mathrm{n}$ & $13(27.7)$ & $13(19.7)$ & 0.322 \\
Hyperlipidemia, $\mathrm{n}$ & $21(44.7)$ & $16(24.2)$ & 0.022 \\
Smoking, $\mathrm{n}$ & $16(34.0)$ & $15(22.7)$ & 0.184 \\
Family history, $\mathrm{n}$ & $9(13.6)$ & $5(10.6)$ & 0.634 \\
Total cholesterol, mg/dl & $195.2 \pm 38.2$ & $199.6 \pm 48.4$ & 0.681 \\
LDL, mg/dl & $112.5 \pm 35.5$ & $125.6 \pm 33.6$ & 0.113 \\
HDL, mg/dl & $46.1 \pm 13.5$ & $46.7 \pm 11.3$ & 0.838 \\
Triglycerides, mg/dl & $150.1 \pm 115.6$ & $132.7 \pm 75.4$ & 0.824 \\
TIMI frame counts & & & \\
$\quad$ LAD & $37.7 \pm 9.3$ & $19.8 \pm 5.4$ & $<0.001$ \\
$\quad$ LCx & $23.0 \pm 6.2$ & $13.7 \pm 3.0$ & $<0.001$ \\
RCA & $26.4 \pm 7.4$ & $14.7 \pm 4.3$ & $<0.001$ \\
$\quad$ Mean & $23.8 \pm 5.1$ & $13.3 \pm 2.6$ & $<0.001$ \\
\hline
\end{tabular}

Values in parentheses represent percentages. $\mathrm{BMI}=$ Body mass index; SBP = systolic blood pressure; $\mathrm{DBP}=$ diastolic blood pressure; $\mathrm{LDL}=$ low-density lipoprotein; $\mathrm{HDL}$ = high-density lipoprotein.

Statistical Analysis

Table 2. The polymorphic SNPs, genotype and allele frequencies of ICAM1 and AGT genes in the patients with CSF and the control group

\begin{tabular}{lcc}
\hline Gene/genotype frequency & $\begin{array}{c}\text { Patients } \\
(\mathrm{n}=48)\end{array}$ & $\begin{array}{l}\text { Controls } \\
(\mathrm{n}=67)\end{array}$ \\
\hline ICAM1, n (\%) & & \\
EE & $9(18.8)$ & $26(38.8)$ \\
KE & $27(56.3)$ & $33(49.3)$ \\
KK & $12(25)$ & $8(11.9)$ \\
Allele frequency & & \\
E & 0.46 & 0.63 \\
K & 0.54 & 0.37 \\
AGT, n (\%) & & \\
TT & $36(75.0)$ & $54(80.6)$ \\
TM & $11(22.9)$ & $12(17.9)$ \\
MM & $1(2.1)$ & $1(1.5)$ \\
Allele frequency & & \\
T & 0.76 & 0.89 \\
M $^{2}$ & 0.24 & 0.1 \\
\hline
\end{tabular}

${ }_{1}^{1}$ p value: 0.013 , OR: 1.96 and CI (95\%): 1.15-3.35.

2 p value: 0.305 , OR: 1.52 and CI (95\%): $1.67-3.42$.
All statistical studies were carried out with the SPPS program (version 15.0, SPSS, Chicago, Ill., USA). All continuous variables were expressed with the mean \pm standard deviation. All measurements were evaluated with the Kolmogorov-Smirnov test and the Shapiro-Wilk test, and a comparison of parametric and nonparametric values between the two groups was performed with the Mann-Whitney U test or Student's t test. Categorical variables (risk factors and polymorphisms) were analyzed using the $\chi^{2}$ test. Risk estimations for the association of CSF with polymorphisms were calculated using ORs and 95\% CIs by comparing genotypic combinations. $\mathrm{p}<0.05$ was accepted as statistically significant.

\section{Results}

The clinical and laboratory findings for the subjects are given in table 1. Baseline demographic parameters were similar in both groups. The TIMI frame counts for each epicardial artery were higher in patients with CSF $(23.8 \pm 5.1)$ than in control subjects $(13.3 \pm 2.6)$, and the difference was statistically significant $(\mathrm{p}<0.001)$.

Genotype properties and allele frequencies are given in table 2 . The $\mathrm{K}$ allele of $I C A M 1$ was significantly related to the possibility of CSF ( $\mathrm{p}=0.013$, OR: $1.96,95 \%$ CI: $1.15-$ 3.35). The AGT M allele and CSF were slightly related but did not reach statistical significance. In 38 patients with hyperlipidemia, the $\mathrm{K}$ allele was significantly related to an increased risk of CSF ( $\mathrm{p}=0.028$, OR: $2.73,95 \%$ CI: 1.11 6.75).

\section{Discussion}

This study showed that the $\mathrm{K}$ allele frequency of ICAM1 was higher in patients with CSF than in controls and that K469E polymorphism was associated with CSF. There was no association between AGT T207M polymorphism and CSF. These findings support the aspect of endothelial dysfunction that may be the underlying mechanism of CSF.

Inflammation and inflammatory factors are important mechanisms in the formation and progression of atherosclerosis [21]. One of these inflammatory factors, ICAM1, is a cell surface glycoprotein released from endothelial cells, macrophages, and lymphocytes and plays an important role in the development of atherosclerotic plaques because it mediates activation of endothelial cells, triggers inflammation, and causes transmigration and adhesion of leukocytes to vascular basal membranes [22]. Epidemiologic studies have shown the relationship between ICAM1 levels and coronary artery disease $[5,23]$. Fur- 
thermore, previous studies demonstrated that ICAM1 gene mutations affect serum levels and activity in the ICAM1 molecule $[24,25]$. In a meta-analysis study, ICAM1 K469E polymorphism was found to be associated with CVD [8]. A study showed that plasma nitric oxide levels were reduced and endothelial functions were impaired in CSF patients, thereby indicating that endothelial dysfunction could cause CSF [25]. In our study the $\mathrm{K}$ allele of the ICAM1 gene increased the risk of CSF almost 2 -fold, thereby supporting the idea that atherosclerotic properties and endothelial dysfunction might be important in pathogenesis of CSF.

AGT, a peptide synthesized in the liver, is one of the basic molecules in RAS; it plays a role in blood pressure regulation, electrolyte balance, and vascular remodeling [26]. Ag-II, an important by-product of RAS, stimulates the release of cytokine from small muscle cells and the release of adhesion molecules from endothelial cells [11]. The AGT gene is located at lq42-43 and consists of five exons [27]. AGT T207M refers to a threonine-to-methionine exchange in codon 207 in exon 2. Borecki et al. [12] reported that $A G T$ gene polymorphism is related to increases in Ag-II levels and hypertension. Findings of the association between AGT gene polymorphisms and coronary artery disease are different in the literature. Although some studies reported that AGT T207M polymorphism was associated with coronary artery disease and hypertension $[14,28]$, others reported that there was no relation $[29,30]$. They concluded that ethnicity of the study population, other genetic polymorphisms and the number of participants may explain the different results. Our study, which included Caucasian patients, showed that the risk of disease was 1.5 times higher but it is not significant. These results may be due to the small size of the study population.
The limitations of this study include the following: (1) the small sample size, (2) it did not examine whether inflammatory markers, including ICAM1, AGT, Ag-II, and $\mathrm{C}$-reactive protein, were affected by polymorphisms and other cytokines, and (3) it did not perform intravascular ultrasonography on patients to determine the extent of intimal thickening and calcifications.

\section{Conclusion}

The present study showed that the well-known relationship of the ICAM1 K allele to endothelial dysfunction and atherosclerosis was associated with CSF. Our findings further support the hypothesis that endothelial dysfunction may be a responsible mechanism for CSF pathogenesis. We recommend that more studies should be done on the etiopathogenesis of CSF to clarify the current findings.

\section{Acknowledgements}

Our study on genetic polymorphisms in CSF was supported by the Research Fund of the Çanakkale Onsekiz Mart University (project No. TSA-2013-99).

We would like to thank Sengul Turunz and Ebru Sik for their help with the laboratory analysis.

\section{Disclosure Statement}

All authors declare that they have no competing interests.

\section{References}

1 Ross R: Atherosclerosis - an inflammatory disease. N Engl J Med 1999;340:115-126.

2 Ceyhan K, Koc F, Ozdemir K, et al: Coronary ectasia is associated with impaired left ventricular myocardial performance in patients without significant coronary artery stenosis. Med Princ Pract 2012;21:139-144.

3 Glagov S, Weisenberg E, Zarins CK, et al: Compensatory enlargement of human atherosclerotic coronary arteries. N Engl J Med 1987:316:1371-1375.

4 Korkmaz H, Akbulut M, Ozbay Y, et al: The relation of intima-media thickness with endothelial function and left ventricular mass index. Anadolu Kardiyol Derg 2010;10:220225 .
5 Ridker PM, Hennekens CH, Roitman-Johnson B, et al: Plasma concentration of soluble intercellular adhesion molecule 1 and risks of future myocardial infarction in apparently healthy men. Lancet 1998;351:88-92.

6 Inwald D, Davies EG, Klein N: Demystified... adhesion molecule deficiencies. Mol Pathol 2001;54:1-7.

7 Pare G, Ridker PM, Rose L, et al: Genomewide association analysis of soluble ICAM1 concentration reveals novel associations at the NFKBIK, PNPLA3, RELA, and SH2B3 loci. PLoS Genet 2011;7:e1001374.

8 Bielinski SJ, Pankow JS, Li N, et al: ICAM1 and VCAM1 polymorphisms, coronary artery calcium, and circulating levels of soluble ICAM1: the multi-ethnic study of atherosclerosis (MESA). Atherosclerosis 2008;201:339-344.

-9 Jiang H, Klein RM, Niederacher D, et al: C/T polymorphism of the intercellular adhesion molecule-1 gene (exon 6, codon 469). A risk factor for coronary heart disease and myocardial infarction. Int J Cardiol 2002;84:171-177.

10 Schmieder RE, Hilgers KF, Schlaich MP, et al: Renin-angiotensin system and cardiovascular risk. Lancet 2007;369:1208-1219.

11 Pueyo ME, Gonzalez W, Nicoletti A, et al: Angiotensin II stimulates endothelial vascular cell adhesion molecule-1 via nuclear factor kappa $B$ activation induced by intracellular oxidative stress. Arterioscler Thromb Vasc Biol 2000;20:645-651. 
12 Borecki IB, Province MA, Ludwig EH, et al: Associations of candidate loci angiotensinogen and angiotensin-converting enzyme with severe hypertension: the NHLBI family heart study. Ann Epidemiol 1997;7:13-21.

13 Joshi PH, Xu H, Lestrange R, et al: The M235T single nucleotide polymorphism in the angiotensinogen gene is associated with coronary artery calcium in patients with a family history of coronary artery disease. Atherosclerosis 2013;226:433-439.

14 Wang WZ: Association between T174M polymorphism in the angiotensinogen gene and risk of coronary artery disease: a meta-analysis. J Geriatr Cardiol 2013;10:59-65.

15 Tambe AA, Demany MA, Zimmerman HA, et al: Angina pectoris and slow flow velocity of dye in coronary arteries, a new angiographic finding. Am Heart J 1972;84:66-71.

16 Sezgin AT, Sigirci A, Barutcu I, et al: Vascular endothelial function in patients with slow coronary flow. Coron Artery Dis 2003;14 155-161.

17 Pekdemir H, Cin VG, Cicek D, et al: Slow coronary flow may be a sign of diffuse atherosclerosis. Contribution of FFR and IVUS. Acta Cardiol 2004;59:127-133.
18 Yalcin AA, Kalay N, Caglayan AO, et al: The relationship between slow coronary flow and angiotensin converting enzyme and ATIIR1 gene polymorphisms. J Natl Med Assoc 2009; 101:40-45.

19 Tanriverdi H, Evrengul H, Mergen H, et al: Early sign of atherosclerosis in slow coronary flow and relationship with angiotensin-converting enzyme I/D polymorphism. Heart Vessels 2007;22:1-8.

20 Gibson CM, Cannon CP, Daley WL, et al: TIMI frame count: a quantitative method of assessing coronary artery flow. Circulation 1996;93:879-888

21 Libby P, Theroux P: Pathophysiology of coronary artery disease. Circulation 2005;111: 3481-3488.

22 Blankenberg S, Barbaux S, Tiret L: Adhesion molecules and atherosclerosis. Atherosclerosis 2003;170:191-203.

23 Hwang SJ, Ballantyne CM, Sharrett AR, et al: Circulating adhesion molecules VCAM-1, ICAM1, and E-selectin in carotid atherosclerosis and incident coronary heart disease cases: the Atherosclerosis Risk in Communities (ARIC) study. Circulation 1997;96:42194225.

24 Iwao M, Morisaki H, Morisaki T: Single-nucleotide polymorphism g.1548G > A (E469K) in human ICAM-1 gene affects mRNA splicing pattern and TPA-induced apoptosis. Biochem Biophys Res Commun 2010;317:729735 .
25 Camsari A, Pekdemir H, Cicek D, et al: Endothelin-1 and nitric oxide concentrations and their response to exercise in patients with slow coronary flow. Circ J 2003;67:10221028.

26 Wang JG, Staessen JA: Genetic polymorphism in the renin-angiotensin system: relevance for susceptibility to cardiovascular disease. Eur J Pharmacol 2000;410:289-302.

27 Benigni A, Cassis P, Remuzzi G: Angiotensin II revisited: new roles in inflammation, immunology and aging. EMBO Mol Med 2010; 2:247-257.

28 Gardemann A, Stricker J, Humme J, et al: Angiotensinogen T174M and M235T gene polymorphisms are associated with the extent of coronary atherosclerosis. Atherosclerosis 1999;145:309-314.

29 Kamitani A, Rakugi H, Higaki J, et al: Association analysis of a polymorphism of the angiotensinogen gene with essential hypertension in Japanese. J Hum Hypertens 1994;8 521-524.

30 Kamitani A, Rakugi H, Higaki J, et al: Enhanced predictability of myocardial infarction in Japanese by combined genotype analysis. Hypertension 1995;25:950-953. 